\title{
TEMPORARY TRANSFORMATIONS TO ACCESS AND EXPERIENCE SUSTAINABLE CITY PUBLIC SPACES
}

\author{
ANDREA BOERI, DANILA LONGO, SERENA ORLANDI, ROSSELLA ROVERSI \& GIULIA TURCI \\ Department of Architecture, University of Bologna, Italy
}

\begin{abstract}
The challenges of contemporary urban regeneration processes call for innovative and sustainable operating models and strategies. Cultural Heritage acknowledgement and valorisation, combined with participatory and engagement practices, can trigger reactivation and re-appropriation of underused urban spaces. Co-design, self-construction and participatory paths, through demonstrative and temporary actions, can generate new dynamics in the public space use, provide effective solutions to tackle climate change, improve outdoor microclimatic comfort conditions, and enhance Cultural Heritage accessibility and knowledge, fostering responsibility for the common good. The implementation of demonstrative interventions, co-created with local administrations, stakeholders and citizens, represents a viable and effective tool to test temporary experimental transformations and to monitor and evaluate their impacts, recalibrating the proposed strategies on a case-by-case basis. This integrated and innovative approach was experimented in the Bologna University area by the EU Horizon 2020 project ROCK - Regeneration and Optimisation of Cultural Heritage in creative and Knowledge cities (GA 730280 ) - through a series of pilot actions. ROCK experimentations are implemented in the historical city centres, enhancing public open space fruition and performative potentials, to generate new resilient processes in terms of environmental sustainability and social inclusion. The co-design and selfconstruction interventions on Piazza Rossini (focused on in this paper) represent short-term and reversible transformations with a long-term impressive and beyond expectations results.

Keywords: co-design, Cultural Heritage, temporary transformations, environmental sustainability, urban regeneration, integrated approach, unconventional uses, co-creation, conservation, ROCK project.
\end{abstract}

\section{INTRODUCTION}

The complex dynamics characterising urban regeneration processes in the contemporary city call for the experimentation of alternative, integrated and sustainable cultural and operative models for the urban and architectural project. The active role played by Cultural Heritage $(\mathrm{CH})$ in sustainable development processes, in the promotion of cultural diversity and in the synergy of competences among all the involved public, institutional and private actors, is supported by the awareness of individual and collective participation in cultural life as a right, as stated by the Council of Europe Framework Convention on the Value of Cultural Heritage for the Society signed in Faro in 2005 [1].

This community commitment finds in co-planning, co-production, self-construction and co-management fundamental steps for experimental urban transformation processes so that being able to possibly achieve long-term results through temporary and pilot actions [2]-[4].

In this context, historic centres are intended as extraordinary laboratories where testing innovative $\mathrm{CH}$-led strategies, capable to reactivate and transform the space of the city, unfolding and revealing unexpressed potential, experimenting unconventional uses and directly involving local communities and stakeholders [5], [6]. The acknowledgment of the positive value of the city as a heritage and common pool resource, according to a vision that combines conservation, enhancement and innovation actions, represents a key aspect of the proposed approach [7].

Several experimentations carried out by the Municipality of Bologna (IT) in the heart of the historic city centre, in collaboration with Fondazione Innovazione Urbana (FIU) - centre 
of analysis, communication, elaboration and co-production on urban transformations to face social, environmental and technological challenges - and the University of Bologna Department of Architecture can contribute to clarify the above described approach, tapping into the creative potential of local users, especially students. These actions are conceived and realised by the ROCK project (Regeneration and Optimisation of Cultural Heritage in creative and Knowledge cities, G.A. 730280), funded in 2017 under the EU Horizon programme in the axis "Climate Action, Environment, Resource Efficiency and Raw Materials", "Greening the Economy", in response to the call "Cultural Heritage as a driver for sustainable growth" (Call ID: H2020-SC5-2016-2017). The project, whose ending will be in December 2020, is leaded by the Municipality of Bologna with scientific coordination of the University of Bologna and involves 10 European Cities and 32 partners [8].

ROCK interprets historic city centres as privileged living laboratories where new models of urban strategies and practices are tested to demonstrate how tangible and intangible $\mathrm{CH}$ can be a powerful engine of regeneration, sustainable development and economic growth for the whole city. ROCK provides new ways to access $\mathrm{CH}$ and to promote perception of shared heritage as collective property, fostering the usability of spaces to all and improving $\mathrm{CH}$ functions from a user perspective. The experimentation of regeneration actions focuses on public open spaces, whose use and performance value allows - through co-design processes - to improve both social inclusion and competitiveness of the city at international level [9].

One of the main actions implemented by the ROCK project is described by the present paper: it concerns experimental spatial and use configurations for Piazza Rossini, a public space in the middle of the University historical area, used for a long time as a parking lot and returned by ROCK to a community role.

\section{INNOVATIVE STRATEGIES FOR URBAN REGENERATION}

The project and process which involved Piazza Rossini, Bologna, are intended as an interesting storytelling opportunity to present possible $\mathrm{CH}$-led urban regeneration strategies: an integrated approach that finds its main components in co-design, reinterpretation of historical memory, experimentation of greening solutions and opportunity of public space re-appropriation.

\subsection{Participation: co-design process}

The ROCK project applies Living Lab methodology [10] to the university area in order to experiment, observe and verify different actions and to improve accessibility to services and to $\mathrm{CH}$. In Bologna, this model has been applied in U-Lab, an iterative process of research and action, which works on viable solutions based on community needs and on urban accessibility through the co-creation of shared services, both oriented towards changing behaviours and modifying space layout.

During the running of the ROCK project, a set of demonstration actions were carried out in the three Replicator cities (Bologna, Lisbon and Skopje), in order to test the replicability and effectiveness of the approach and of the related models successfully implemented in seven Role cities. As regards Piazza Rossini case study in Bologna, the preliminary considerations were born during the participatory laboratory "U-Lab" which took place on this specific area and attended by over 250 people. From an active comparison and exchange of ideas between the main involved stakeholders (institutions, associations, students, etc.), the need to restore a social dimension to the square emerged, paying particular attention to greening and lighting as design elements.

During the participatory phases some suggestions were collected and placed at the base of Piazza Rossini regeneration project: [the need to] create a "Light Plan" to ensure good 
visibility in the area, a fundamental element to increase the perception of safety, in particular for deaf people and to lead the public visitors towards new rest and stay areas; [the need to] provide places reserved for children with urban furniture suitable for playing and resting; [the need to] make the square more democratic, to serve everyone and not just cars or a few categories of people, rethinking its primary and secondary uses [11].

\subsection{Greening: testing shared sustainable strategies and solutions}

As will be explained later more in detail, the basic idea for the renovation of piazza Rossini is the transformation into a green area. The choice of the meadow as a temporary solution for urban regeneration fits in the European framework, which sees cities at the forefront of efforts to tackle climate change. Examples of similar approaches applied to historical spaces can be found in several temporary interventions. For instance, in 2017 Plaza Mayor in Madrid was covered by a giant meadow of natural grass that allowed citizens and tourists to sit down and enjoy the square from a new perspective, reflecting about how green can transform the way of living and using public spaces. The simple, but impressive, project was realized by the artist SpY in the context of "Cuatro Estaciones", an urban art program run by the Madrid City Council to celebrate the Plaza 400th anniversary [12]. Likewise, in Italy some best practices of temporary greening - "Piazza Vecchia Fiorita", Bergamo, 2014; "Un Altro Parco in Città", Pistoia, 2019; "Il prato temporaneo in Piazza Grande", Arezzo, 2019; "La città che foglia e fiora", Design Week, Genoa - are arising the discussion on the dynamics of communities and places re-activation and are generating a debate around the theme of sustainability in historic city centres.

Heat waves phenomenon in European cities is increasingly frequent. As highlighted by "IdroMeteoClima Report" [13], in 2019 the urban areas in the Po Valley recorded up to 60 tropical nights (with a minimum temperature above $20^{\circ} \mathrm{C}$ ) and 80 hot days (with a maximum temperature above $30^{\circ} \mathrm{C}$ ). Future climatic scenarios, elaborated by Arpae Emilia-Romagna, show a probable average temperature increase in Bologna of two degree for the period 2021-2050 compared to 1961-1990, with the strongest anomalies that may occur during the summer period, leading to a consequent increase in heat waves [14]. The city of Bologna must therefore adapt to climate change and rising temperatures, with concrete actions that follow its extensive and integrated urban planning - Urban Environment Adaptation Plan (BlueAp), Action Plan for Sustainable Energy (PAES), Mayors Adapt initiative, new Urban General Plan (PUG) with its Resilience goal. This can be done both with demonstrative and symbolic actions aimed at changing users' behaviour and with real "devices" that help to reduce temperatures in urban spaces. The meadow in Piazza Rossini responds to both objectives in a demonstrative way.

As was pointed out by the report "Rigenerare la città con la natura" [15] and by other Emilia-Romagna Region documents [16], [17], cities are encouraged to enhance the presence of urban greenery, due to its essential function of thermal regulation and resilience to climate change. In fact, a vegetative element, such as a lawn, leads to a reduction in the reflection of infrared rays at night, and it also allows a beneficial excursion between day and night [18]. Furthermore, some species of vegetation could have a mitigating effect on the presence of pollutants in the atmosphere, by capturing the particulate matter $\left(\mathrm{PM}_{10}, \mathrm{PM}_{2.5}\right)$ thanks to the roughness of the leaf surfaces.

In order to test the efficiency of greening strategies implemented by the ROCK project in Piazza Scaravilli - a public space overlooking Via Zamboni and placed a few meters away from Piazza Rossini - the University of Bologna analysed in detail the effects of the intervention through simulations performed with ENVI-Met software [19] and through the 
data collection from the environmental sensors placed in the area by the Acciona company, a project partner. Simulations show significant temperature variations in view of "Malerbe" project, demonstrating how even a small greening intervention can significantly contribute to the heat island mitigation [20].

\subsection{Opportunity: An active demonstration of re-appropriation of public space}

The first temporary project for Piazza Rossini was successfully embraced by the citizens, with an average daily presence of over 30,000 visitors - monitored through 10 crowd analysis sensors with WiFi-GPS technology installed in the area - who did not just transit through the area but spent some time in the square. During the week of experimentation in September 2019 , an increase in flows with an average of 27,000 daily and a peak in the day of around 36,000 visitors have been registered: the weekly inflows amounted to 200,000 visitors.

The installation was abundantly commented upon on social media, on blogs and on social networks. Furthermore, a large number of citizens, local associations and social entrepreneurial activities (e.g. Salvaiciclisti, Dynamo, Kilowatt), professional intermediaries (Ordine degli Architetti Bologna) and ad-hoc initiatives (Strade Aperte Bologna) enthusiastically endorsed the initiative as a first step towards a future vision and action for the city. The positive reaction came also from citizens, also supported by a spontaneous collection of signatures called "A meadow in Piazza Rossini", showing how a reversible intervention, carried out in self-construction and in a few days, can trigger dynamics of re-activation of communities as well as places, raising awareness on climate change and generating a heated debate around the theme of sustainability of historic centres.

Emerging from the covid-19 pandemic, cities are embracing several strategies to grant wider and healthier public space, to create safe and attractive situations for visitors and to provide inclusive environments for the largest categories of citizens to retrieve the city public social dimension, compromised by the forced distancing. In this context "Strade Aperte" initiative, born in Bologna, in addition to supporting with a positive response the Piazza Rossini project, proposes city widespread interventions and temporary installations. The aim is to promote new forms and uses of public spaces, fostering the suburb's enhancement through the reactivation of proximity spaces and creation of suitable streets for pedestrians and bicycles [21].

\section{TEMPORARY AND PILOT TRANSFORMATIONS OF PUBLIC SPACE: PIAZZA ROSSINI PROJECT IN BOLOGNA}

The experimentations on Piazza Rossini are part of a broader strategy of actions that systematically involved the main public spaces of the university district - as recalled by the name of the initiative, "The Five Squares" of the University Zone - developed in synergy with the programming of "Bologna Design Week" and "Researchers' Night" in September 2019 (Fig. 1).

The Five Squares wanted to represent a proposal and an event dedicated to urban regeneration, optimization and accessibility of $\mathrm{CH}$, incentive and promotion of public space care through the deployment of its potential and the testing of unconventional uses, according to an environmental sustainability perspective.

Piazza Giacomo Rossini is a public space of great historical and architectural value. The square is defined by many relevant buildings: the Basilica San Giacomo Maggiore, the former convent of Santa Cecilia, home of "Giovan Battista Martini" Music Conservatory, the late Renaissance front of Palazzo Magnani (currently used as a bank office) that preserves 


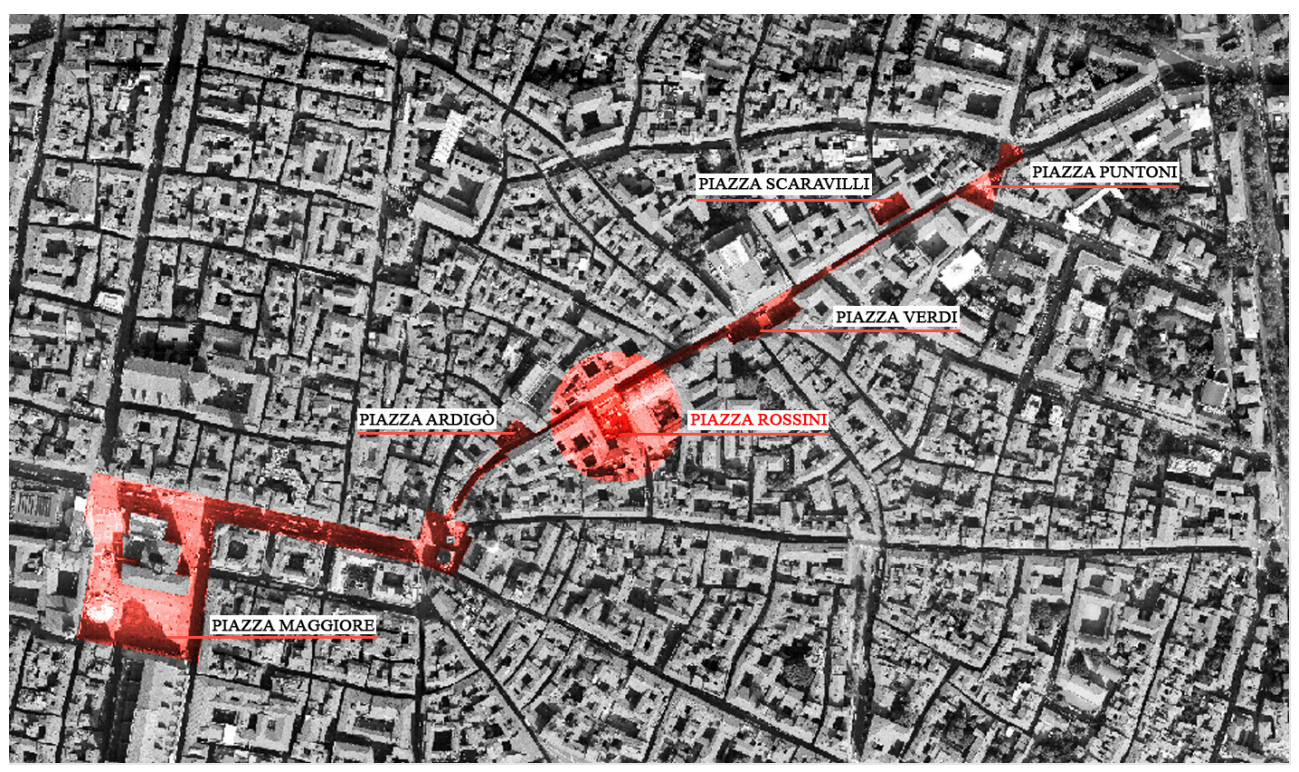

Figure 1: The U-Zone system of open public spaces involved in The Five Square workshop. The red circular spot points out Piazza Rossini, object of the temporary urban transformation projects. (Source: ROCK Project, 2019 [8].)

remarkable frescoes and an open-to-public picture gallery, Palazzina Lambertini, an example of eighteenth-century civil architecture and the sixteenth-century Palazzo Malvezzi, current headquarters of the "Metropolitan City" public body of Bologna.

The Square has always had the function of public parking area for cars and bicycles, preventing its use as an urban space for stopping, gathering and socialize: pedestrians could only circulate on the narrow sidewalk margin next to the road lane, while the presence of the parked vehicles in the middle of the area interfered with the view of the surrounding architectural scenario.

The temporary design actions provided in Piazza Rossini, implemented through two main and successive phases of transition, led to the permanent transformation path of the square into a new pedestrian and regenerated space for both citizens and city users. The unexpected perception of the square space proposed by the temporary-reuse project, in addition to the experimentation of new uses, offered the opportunity to rediscover and appreciate the details of the architecture overlooking the square and recall an historical reference. In fact, several historical documents - maps and views - represent Piazza Rossini area with a different pavement surface compared to other squares or roadways: detail of Bononiensis ditio in the Vatican "Sala Bologna", dating back to 1575 , shows a green vegetable pavement for the buildings internal courtyards; similarly, the View of Piazza Rossini by F.B. Werner, dated to 1732, represent a cobblestone floor that defines the area of the ancient churchyard or cemetery of San Giacomo Maggiore Basilica, marking his different surface texture. The choice of the vegetable lawn was suggested by these archival documents, searched and deeply analysed by the students involved in the Five Square project. 


\subsection{Green Please! The meadow you don't expect}

"Green Please! The meadow you don't expect" is the name of the project of the first temporary redefinition of the square, as a result of a shared and participatory process. The project was conceived through a co-design and co-construction workshop that involved students of the Department of Architecture of the University of Bologna, coordinating with FIU. The project envisaged the partial occupation of the parking area, about $400 \mathrm{sqm}$, through the setting up of a vegetable meadow in rolls, which covered the surface corresponding to twenty parking spaces, eleven motorcycle parking and the relative manoeuvring area. Furthermore, in a decentralized position, an iconic "Maxxi Poppy" outdoor floor lighting fixture was positioned. Maxxi Poppy is designed and produced by Viabizzuno srl, a partner company of the ROCK project (Fig. 2). The construction system of the whole installation was designed to be self-built by the workshop unskilled participants, with limited economic resources. The self-construction set-up, carried out in about three days of work, was itself conceived as a performative event, actively demonstrating the re-appropriation of space and its possible and unconventional use.

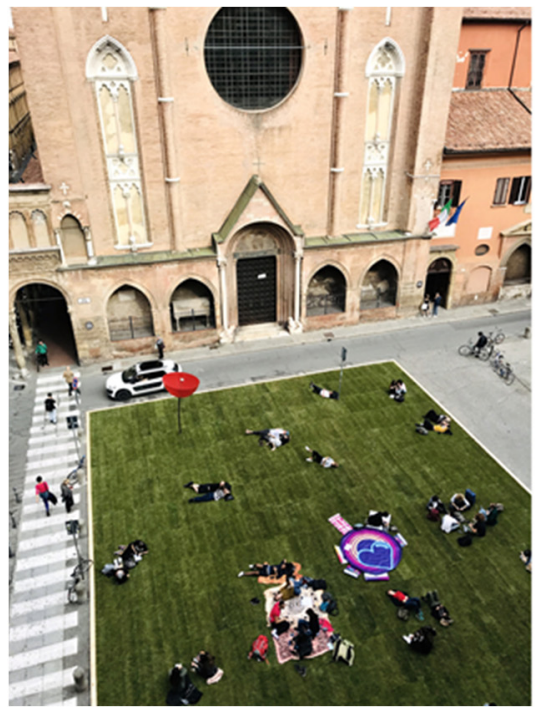

(a)

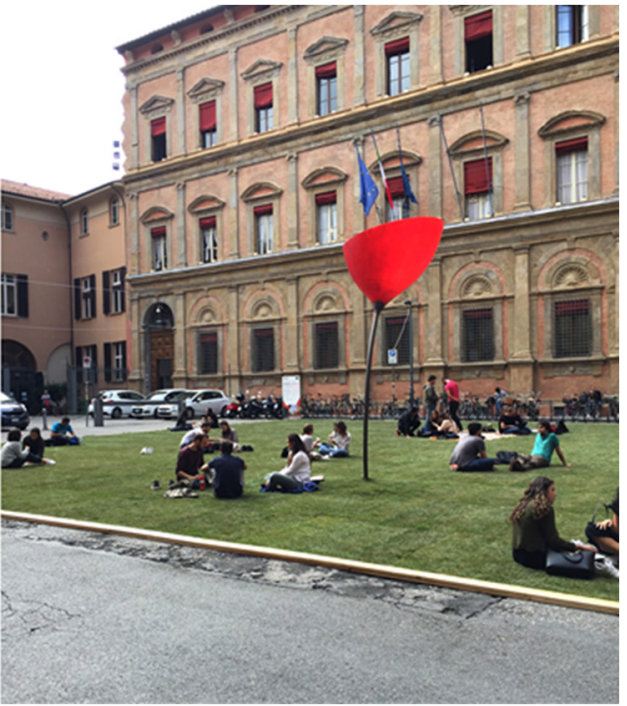

(b)

Figure 2: (a) Aerial views of the completed "Green Please!" set-up; (b) the Square with the Maxxi Poppy and, in the background, Palazzo Malvezzi. (Source: ROCK Project, 2019 [8].)

During the days of the "Bologna Design Week" (22-29 September 2019) and the Researchers' Night (27 September 2019), visitors had the opportunity to sit, gather and freely stop on the green carpet. Several activities, such as concerts, lectures and workshops, were organized on the meadow during the experimentation days, while other initiatives were born in a spontaneous way.

The project aimed both to experiment new uses in public spaces in the heart of the university area and to offer the opportunity to rediscover and appreciate the view and the details of the architectural treasures overlooking the square, not possible in the previous 
configuration. In response to the positive feedback obtained from citizenship and from the sharing of project aims and outcomes, the Municipality of Bologna established that the square will be no longer occupied by cars, starting a transition path that will transform definitively the square into pedestrian. The installation, designed and built to stay on site just for a week, was extended for additional ten days.

Following the necessary removal of the first set-up, the square remained off-limits to cars and the area was temporarily cordoned off to prevent access to vehicles. Another new temporary configuration became necessary, requiring the construction of a new transitional configuration of the expected duration of about a year, so to allow the Municipality to develop the project of the permanent configuration of the square.

\subsection{Green Please 2.0! The green you don't expect}

"Green Please 2.0! The green you don't expect. A project for piazza Rossini in transition" is the designed answer for the second temporary transition project, implemented and realized by the FIU during the 2020 summer, with the scientific collaboration of the Department of Architecture - University of Bologna and BAG Studio.

The new project is on the same line of the first one, in order to make citizens perceive that the design intentions are following a similar thematic trend. At the same time, the new square configuration represents a further development of the previous one, since its longer stay implies design and technological solutions of a higher level of complexity. The guide principles of the implemented solution are: absolute reversibility - given the expected period of stay - usability, adequate durability, ease of maintenance and subsequent restoration of the previous state of places. In addition, the project has educational, social and awareness purposes on ecological issues, environmental and common $\mathrm{CH}$ care.

The temporary urban installation is basically a new meadow, bounded by a wooden edge $15 \mathrm{~cm}$ high, which contains the soil substrate. A ramp makes it accessible for all, overcoming the small height difference (Fig. 3). The vegetable footboard is partially occupied by planters that house small ecosystem of plants, in line with other experimental actions of urban green injection within the historical university area developed by the ROCK project: the temporary installation "Malerbe" (Piazza Scaravilli, 2017-2019) [22] and the pocket garden "U-Garden" (Terrace of the Municipal Theatre in Piazza Verdi, summer 2019) [23] (Fig. 4).

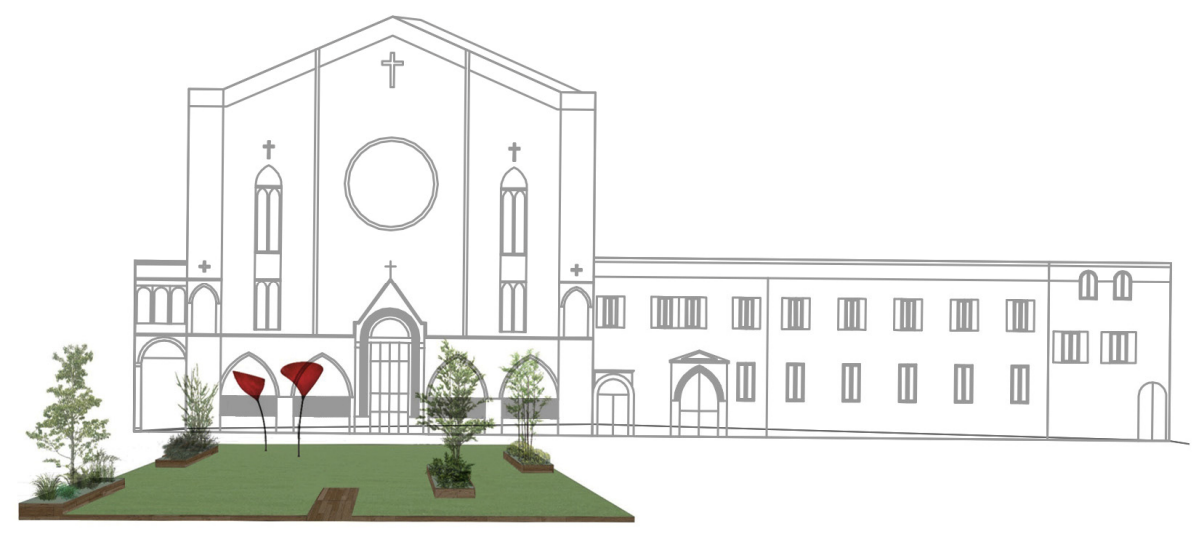

Figure 3: Concept of the second temporary project "Green Please 2.0! the green you don't expect”. (Source: ROCK Project, 2020 [8].) 


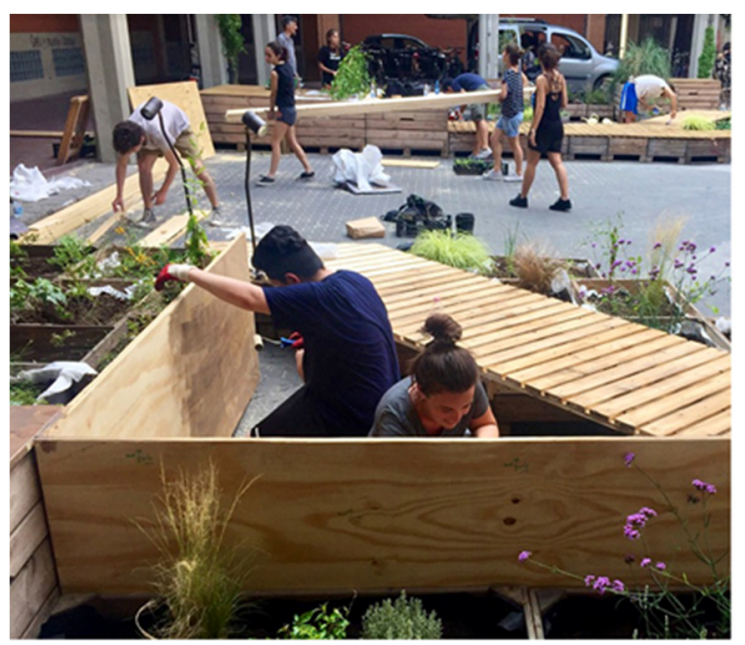

(a)

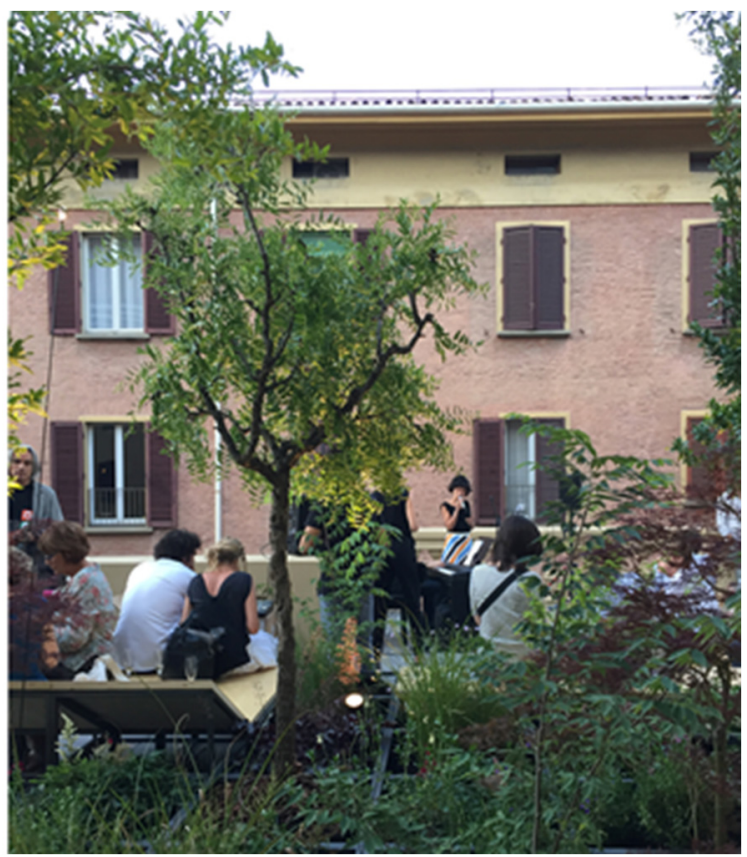

(b)

Figure 4: (a) "Malerbe" temporary construction in Piazza Scaravilli, outcome of a co-design and co-construction workshop coordinated by the Department of Architecture, University of Bologna with Centro Antartide, that changes the parking area into a dynamic urban garden; (b) "U-Garden", the project for the pocket garden realized on the terrace of the Municipal Theatre of Bologna in the summer of 2019, as part of the actions implemented by "The Five Square" workshop. (Source: ROCK Project, 2019 [22], [23].) 
The surface occupied by the system of wooden tanks extends for about $30 \mathrm{sqm}$ and contains shrubs, perennial herbaceous plants, aromatic herbs and ornamental grasses. These are all native plants, selected to ensure biodiversity, with different characteristics changing with seasons, to make the green area interesting all year round; trees of first size, about 3/4 meters high, have also been planted. During the night, two "Maxxi Poppy" (by Viabbizuno, ROCK-partner) light up the space.

Beyond the functional aspect, the planters are entrusted with the transmission of the messages they report written on the vertical sides, in white characters. The writings, sized in height to be legible by those passing by through Via Zamboni, explain in different languages the transience of the project and aim to communicate respect and responsibility towards the public place.

They convey the message that the installation does not correspond to the definitive asset of the square, clarifying the transitory nature of the intervention, which dictated conditions, expressive possibilities and available budget.

The installation was open to the public from the beginning of July 2020 and the Municipality of Bologna, in collaboration with FIU, promoted a series of open and cultural activities to be carried out on the lawn of Piazza Rossini - "Take care of U. Encounters and stories on the meadow" - as part of the summer activities of "Bologna Estate". Taking advantage of this rediscovered space, the initiative is fostering a sense of appropriation, responsibility and care for $\mathrm{CH}$ and common public spaces (Figs 5-7).
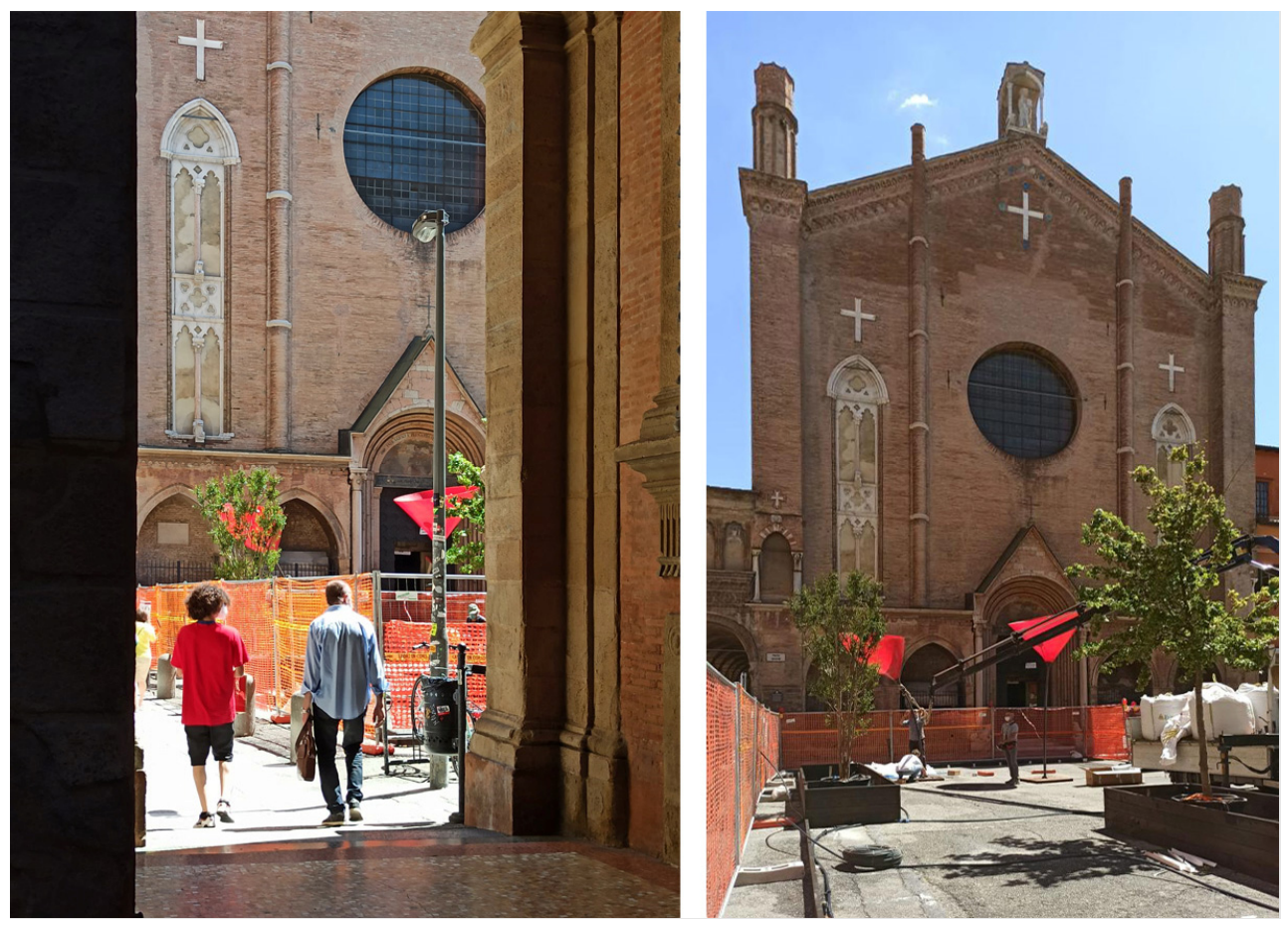

Figure 5: The "Green Please 2.0" project under construction, June 2020. (Source: ROCK Project, 2020 [8].) 


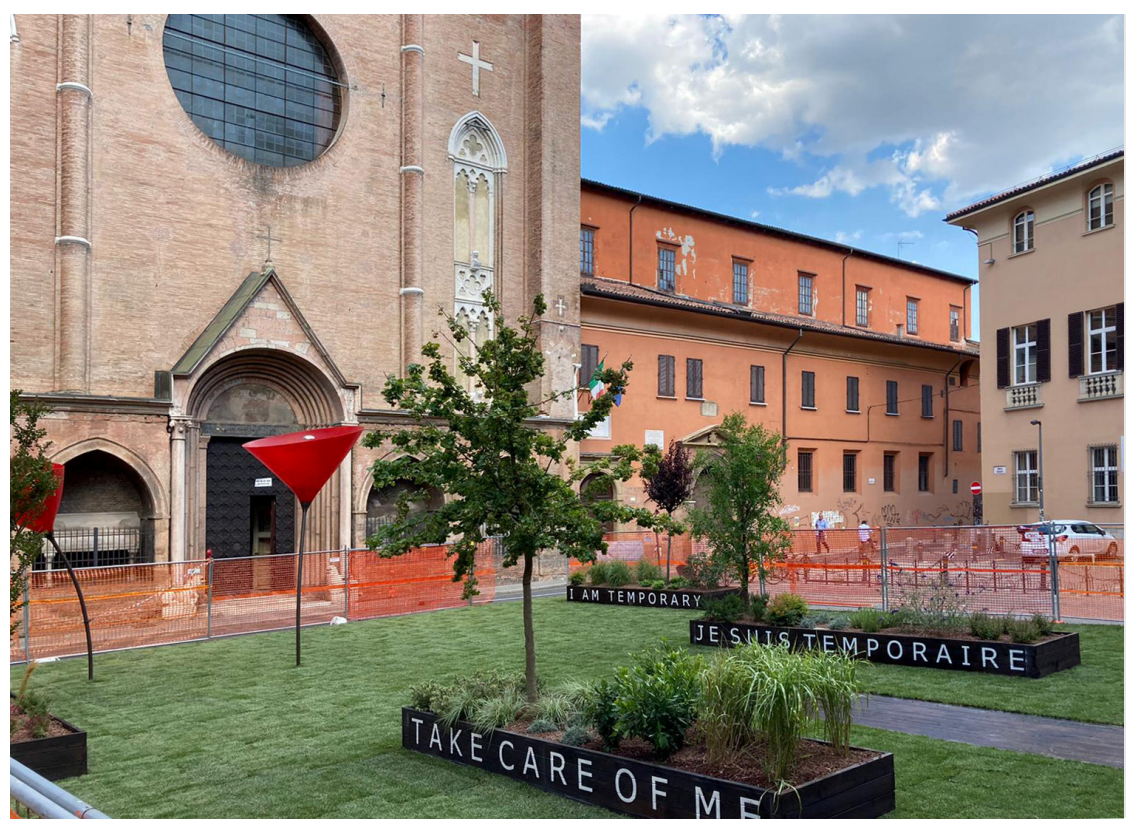

Figure 6: The "Green Please 2.0" installation completed, June 2020. (Source: ROCK Project, 2020 [8].)

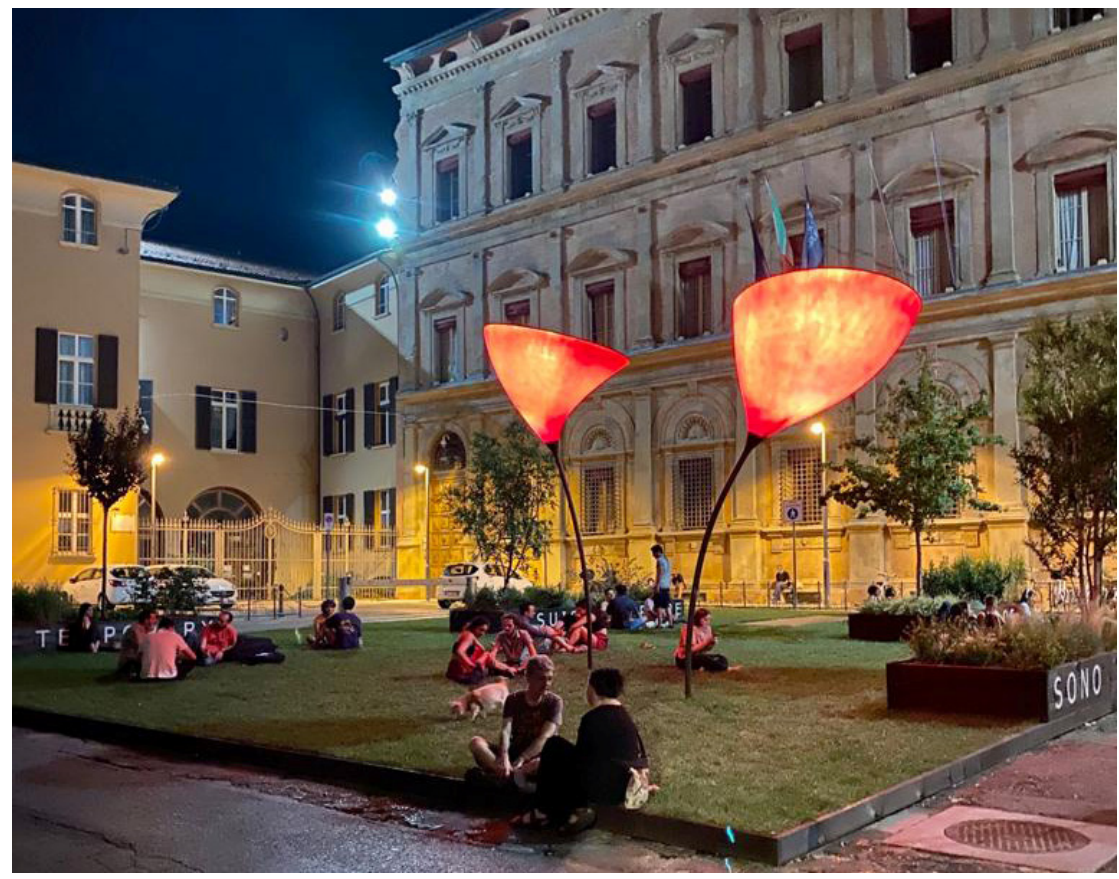

Figure 7: The "Green Please 2.0" project by night, July 2020. (Source: ROCK Project, 2020 [8].) 


\section{CONCLUSIONS}

The co-designed greening interventions for Piazza Rossini are temporary and are characterized by an experimental nature: pilot experiences, which - although of limited duration in time - aim at achieving long-term impacts and results. The rediscovery and reappropriation of this public space by citizens must correspond to the contextual construction of a sense of collective responsibility towards common $\mathrm{CH}$.

The temporary solutions realized by the project will accompany city-users and citizens along the pedestrianization process of the square, proposing perceptions and uses in stark contrast to the previous car park consolidated function. Where there were only cars and where it was not even possible to safety walk, a lawn is allowing to stop and appreciate the precious architectures facing the square, promoting the educational function of the city public spaces and a more responsible behaviour towards both the natural and built environments.

The project - in addition to the spatial transformation of the public square and its changing perception - generated a heated debate among architects, urban planners, intellectuals, art historians, citizens and citizens' associations, on issues such as the compatibility between the character of the historical urban structure and the proposed greening intervention, the opportunity to respond to the need for relationships, sociability, and community spaces toward the risk of improper uses. A green lawn in the heart of the university area of Bologna could enable uses that could be considered "not appropriate" (wandering, sunbathing, making noise, etc.) to the historical and institutional context. However, how many "appropriate" uses could it generate? Even if the green presence is very limited in the area, the problems related to the "movida" seem to be so relevant to overshadow all other potential scenarios and benefits. The challenge focuses on the collective responsibility of the Piazza Rossini community and the projects aim is to emphasize the importance of taking care of common places, strengthening their sense of re-appropriation and raise awareness of pressing climate issues. The numerous reactions came from citizens at the first and second testing steps, showed how a reversible intervention, carried out in self-construction, with limited resources and in a few days, can trigger important community dynamics, raising awareness on climate change and generating a heated debate around the theme of sustainability of historic centres.

The experimentation will continue during the next year, waiting for the square to assume its final configuration: a period during which the city will have the opportunity to learn to respect, enhance and make grow, like a vegetable seedling, this rediscovered place, and find more pondered answers to the issues that the current installation has raised.

The temporary Piazza Rossini projects - as well as "Strade Aperte", "Malerbe", "U-Garden" or other greening initiative cited - fit in the general tendency to provide openness spaces, first for testing, then to review, correct and test again solutions for cities that are constantly changing and evolving, in the attempt to slow down the threat of climate and global changes with small local successful efforts [24]. They finally fit in a future vision for cities that are changing their times and rhythms (e.g. slow-fast city integration) enabled by a peculiar use of technologies as empowering devices, used to monitor local small-scale experiments and verify their effects for an greener envisaged future cities.

\section{ACKNOWLEDGEMENTS}

The ROCK projects is co-financed by the European Union within the H2020 Framework Programme [ROCK G.A. No.730280], in the axis "Climate Action, Environment, Resource Efficiency and Raw Materials", "Greening the Economy", in response to the call "Cultural Heritage as a driver for sustainable growth" (Call ID: H2020-SC5-2016-2017). 


\section{REFERENCES}

[1] Council of Europe, Framework convention on the value of cultural heritage for society, Faro, 27.X.2005.

[2] Sharifi, A. et al., Conceptualizing dimensions and characteristics of urban resilience: Insights from a co-design process. Sustainability, 9, 2017.

[3] Nesti, G., Co-production for innovation: the urban living lab experience. Policy and Society, 37, pp. 310-325, 2018.

[4] Boeri, A., Longo, D., Mariotti, C. \& Roversi, R., Planning long term management for historic cities. The ROCK integrated management plan. International Journal of Design \& Nature and Ecodynamics, 14, pp. 311-322, 2019.

[5] Boeri, A., Gaspari, J., Gianfrate, V., Longo, D. \& Pussetti, C., Il riuso adattivo dei centri storici. Bologna e Lisbona: soluzioni per la rigenerazione urbana. TECHNE Journal of Technology for Architecture and Environment, 12, pp. 230-237, 2016.

[6] Djalali, A. \& Orlandi, S., Il laboratorio di co-progettazione come strumento di ricercaazione per il progetto dello spazio pubblico. Bologna-Bogotá: Ricerca e Azione per lo Spazio Pubblico, Bononia University Press (BUP): Bologna, pp. 60-71, 2019.

[7] Council of the European Union, Conclusions on cultural heritage as a strategic resource for a sustainable Europe. www.consilium.europa.eu/uedocs/cms_data/docs/ pressdata/en/educ/142705.pdf. Accessed on: 10 Aug. 2020.

[8] ROCK Project website. https://bologna.rockproject.eu/. Accessed on: 10 Aug. 2020.

[9] Babalis, D., Heritage open space in transformation. Changing Attitudes, Altralinea edizioni, pp. 78-86, 2018.

[10] Dane, G.Z, Derakhshan, S., Ettefagh, T., Massari, M., Gianfrate, V. \& Bigi, M., Participatory mapping of citizens' experiences at public open spaces: A case study at Bologna Living Lab. REAL CORP 2020: Shaping urban Change. Livable City Regions for the 21st Century: Proceedings of 25th International Conference on Urban Planning, Regional Development and Information Society, Wien, CORP-Competence Center of Urban and Regional Planning, pp. 645-654, 2020.

[11] ROCK Project, U-LAB Incontri sui luoghi. Dossier introduttivo Piazza Rossini. www.fondazioneinnovazioneurbana.it/images/PROGETTO_ROCK/dossierRossini.pdf. Accessed on: 10 Aug. 2020.

[12] “Cesped", Plaza Mayor (Madrid), 2017. https://divisare.com/projects/384566-spyruben-p-bescos-grass. Accessed on: 10 Aug. 2020.

[13] Arpae, Rapporto IdroMeteoClima Emilia-Romagna 2019, 2020. www.arpae.it/cms3/ documenti/_cerca_doc/meteo/rapporti_annuali/idrometeoclima2019.pdf. Accessed on: 10 Aug. 2020.

[14] Regione Emilia-Romagna, Proiezioni climatiche 2021-2050 area urbana di Bologna. https:/ambiente.regione.emilia-romagna.it/it/cambiamenti-climatici/gli-strumenti/ forum-regionale-cambiamenti-climatici/scenari-climatici-regionali-per-areeomogenee-1/schede/bologna-scheda-proiezioni-climatiche.pdf. Accessed on: 10 Aug. 2020.

[15] Dessì, V., Farnè, E., Ravanello, L. \& Salomoni, M.T., Rigenerare la Città con la Natura. Strumenti per la Progettazione degli Spazi Pubblici tra Mitigazione e Adattamento ai Cambiamenti Climatici, Maggioli Editore, 2016.

[16] Regione Emilia-Romagna, LR 24/2017 “Disciplina regionale sulla tutela e l'uso del territorio".

https://demetra.regione.emilia-romagna.it/al/articolo?urn=er:assemblealegislativa: legge:2017;24. Accessed on: 10 Aug. 2020. 
[17] Regione Emilia-Romagna, Strategia per la mitigazione e l'adattamento della Regione Emilia-Romagna, 2018. https://ambiente.regione.emilia-romagna.it/it/cambiamenticlimatici/temi/. Accessed on: 10 Aug. 2020.

[18] Bowler, D.E., Buyung-Ali, L., Knight, T.M. \& Pullin, A.S., Urban greening to cool towns and cities: A systematic review of the empirical evidence. Landscape and Urban Planning, 97, pp. 147-155, 2010.

[19] ENVI-met software. www.envi-met.com/.

[20] Gaspari, J. \& Fabbri, K., A study on the use of outdoor microclimate map to address design solutions for urban regeneration. Energy Procedia, 111, pp. 500-509, 2017.

[21] “Strade aperte a Bologna: c'è fame di spazio!". www.change.org/p/sindaco-dibologna-un-prato-in-piazza-rossini-5aacb378-cd22-4f26-af79-c8bfdbf4ced1. Accessed on: 10 Aug. 2020.

[22] ROCK Project, Dossier Piazza Scaravilli, 2019. http://dati.comune.bologna.it/node/ 3509. Accessed on: 10 Aug. 2020.

[23] FIU, U-Garden. La terrazza verde del Teatro Comunale, 2019. www.fondazioneinnovazioneurbana.it/45-uncategorised/2042-u-garden-la-terrazzaverde-del-teatro-comunale. Accessed on: 10 Aug. 2020.

[24] Gianfrate, V. \& Longo, D., Urban Micro-Design. Tecnologie Integrate, Adattabilità e Qualità degli Spazi Pubblici, FrancoAngeli: Milano, 2017. 